\title{
Erratum to: Screening of Blood Levels of Mercury, Cadmium, and Copper in Pregnant Women in Dakahlia, Egypt: New Attention to an Old Problem
}

\author{
Shimaa M. Motawei $^{1} \cdot$ Hossam E. Gouda $^{2}$
}

Published online: 31 July 2017

(C) Springer Science+Business Media, LLC 2017

Erratum to: Biol Trace Elem Res (2016) 171:308-314

https://doi.org/10.1007/s12011-015-0525-y

The authors would like to indicate the below correction to the above referenced article.

In the section "Apparatus" first sentence: The word "lead" should be deleted. The correct sentence should read:

Measurement of trace elements was performed by a model Perkin-Elmer double-beam 2380 atomic absorption spectrophotometry (AAS) that adapted Perkin-Elmer hollow-cathode lamps and conventional $10-\mathrm{cm}$ slot burner heat for an airacetylene flame.

The authors regret the oversight.

The online version of the original article can be found at https://doi.org/ 10.1007/s12011-015-0525-y

Shimaa M. Motawei

Shimaa_motawei@yahoo.com

1 Forensic Medicine \& Clinical Toxicology Department, Faculty of Medicine, Mansoura University, Mansoura, Egypt

2 Obstetrics \& Gynaecology Department, Faculty of Medicine, Mansoura University, Mansoura, Egypt 